\title{
Operation Analysis of Hydraulic Excavator with Different Operation System
}

\author{
Akihiko NISHIYAMA ${ }^{\mathrm{a}}$ and Masaharu MOTEKI ${ }^{\mathrm{a}}$, Kenichi FUJINO ${ }^{\mathrm{a}}$, Takeshi HASHIMOTO \\ apublic Works Research Institute \\ E-mail: nishiyama@pwri.go.jp, moteki@pwri.go.jp, fujino@pwri.go.jp, t-hashimoto@pwri.go.jp
}

\begin{abstract}
-
Unmanned construction with remotely operated construction machines is actively used a means of construction work in dangerous areas with no access to people such as rehabilitation work sites damaged by natural disasters including earthquakes or volcano eruptions. Unmanned construction is expected to progress in the field as a quick and safe technique for restoration from disaster damage.

However, unmanned construction with remotely operated hydraulic excavators is known to be much poorer in work efficiency than construction work with directly operated machines. The Public Work Research Institute (PWRI) has been promoting research on the actual status of, causes of, and solutions to reduced work efficiency of unmanned construction with remotely operated hydraulic excavators.
\end{abstract}

Our research focused on the impact that different operation systems of a remotely operated hydraulic excavator had on the work efficiency with the aim of obtaining knowledge that will help improve the work efficiency of unmanned construction.

To fulfil this purpose, a comparative experiment was conducted using a few operation systems with changed parameters of operation interface for a hydraulic excavator.

The data obtained from the experiment were analysed for each operation system and work element, with important points that express differences in work time and work efficiency analysed for clarification. Causes that resulted in differences were also discussed using video records.

Based on the experiment, the authors successfully clarified the status of the impact of interface operability for a remotely operated hydraulic excavator on the work efficiency and obtained knowledge that will lead to improved work efficiency of unmanned construction.
Keywords -

Remote control technology, Disaster, Construction machine, Hydraulic excavator, Operation interface Introduction

\section{Introduction}

Unmanned construction, construction with remotely operated construction machines, is actively used as means of construction work in dangerous areas that people have no access to, such as rehabilitation work sites damaged by natural disasters including earthquakes or volcano eruptions. Unmanned construction is expected to progress in the field as a quick and safe technique of restoration from disaster damage.

However, remote operation of hydraulic excavators conducted as unmanned construction sites is known to be much poorer in work efficiency than construction work with manned machines. The Public Work Research Institute (PWRI) has been promoting research on the actual status of, causes of, and solutions to reduced work efficiency of unmanned construction.

Preceding research on the efficiency of the remote operation of the hydraulic excavator were conducted in a flow of the following (1) to (3).

(1) The work of the provisions was carried out in two ways of remote operations and boarding operation of the hydraulic excavator. I grasped the reality of the work efficiency decreases by remote control ${ }^{[1]}$.

(2) The work of the provisions were carried out multiple times by multiple operators. It was analyzed for the impact on the working efficiency decrease due to getting used to the work ${ }^{[2]}$.

(3) Comparison of remote operations and boarding operation, a comparison of the novice and skilled person, were carried out by focusing on the gaze point in the operation and working time ${ }^{[3]}$.

Based on these research results, we will further pursue the cause of the working efficiency decrease of the remote control. Therefore, in this study, we aimed to 
understand the impact on efficiency due to the difference in operation interface in the remote operation.

In our research, a comparative experiment was conducted based on a model task related to four different operation methods with different operation conditions (to be explained later). The time taken to complete a single run of the model task (hereinafter the cycle time) was measured, and the task work was filmed.

The time taken by a directly operated machine was used as the benchmark for comparison purposes. The cycle time recorded was divided into that of the excavation work and that of traveling, and each work efficiency was compared by the method of operation. We also discussed whether or not the skill of the operator (speediness of work execution) had any effect on the work efficiency depending on the operation interface.

\section{Purpose of Research}

The purpose of our research is to determine the actual status of interface operability as a factor that affects the work efficiency of unmanned construction and obtain knowledge that may help improve work efficiency.

\section{Experiment Method}

\subsection{Experiment field}

The experiment field was set up as shown in Fig. 1.

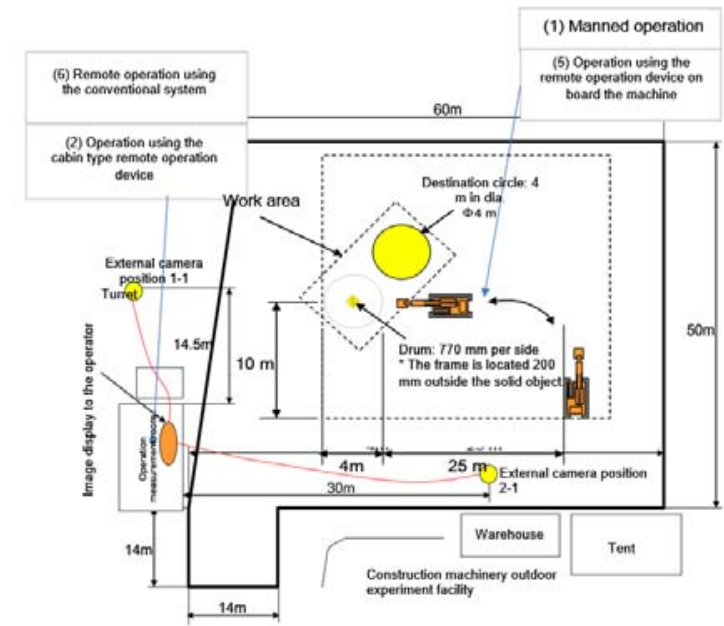

Fig. 1 Overview of the experimental field

\subsection{Outline of the model task}

The model task developed by preceding research was used for our study ${ }^{[1]}$ :

(1) The operator drives a construction machine to the designated work position (near the work area) shown in the experiment field (Fig. 1);

(2) The machine grabs a solid object with its bucket and moves from the initial position to the destination circle, instead of conducting excavation work; and

(3) The machine grabs the solid object with its bucket and moves from the destination circle to the initial position. (The initial position is set as a square area with each side measuring $770 \mathrm{~mm}$, and a solid object is placed in that square. When the operators fail to place the object inside the square, they lift it up again and place it in the square.) The solid object to be handled by the machine is a drum $(570 \mathrm{~mm}$ in diameter, $760 \mathrm{~mm}$ in height, about $100 \mathrm{~kg}$ in weight, and 2,000 $\mathrm{mm}$ in handle height).

\subsection{Equipment and materials for the experiment}

\subsubsection{Hydraulic excavator}

A remotely operated hydraulic excavator (12-ton class with a bucket capacity of $0.5 \mathrm{~m}^{3}$ ) was used.

\subsubsection{Video equipment}

Two cameras were placed in the field (Fig. 1) to film images for the operator's remote operation in an operation measurement room. Camera images (analog video, $30 \mathrm{fps}$, equivalent to $720 \times 480$ ) from a total of three cameras, including the said two and one installed on the hydraulic excavator (Fig. 1) were shown on monitors in the operation measurement room. Operators remotely operated the machine while viewing those monitors. Vertical and lateral rotation and zooming of the external cameras were performed by a dedicated camera operator.

\subsection{Comparative experiment conditions}

Four operation conditions were used in this experiment.

"Operation of a machine by an operator in the machine" (hereinafter "manned operation") and "remote operation by an operator in the machine" were compared to analyze the effect of the differences in the manned operation interface.

"Remote operation using the conventional system" and "remote operation using the cabin-type remote control system" were compared to analyze the effect of the differences in the remote operation interface. 
Operation interfaces of manned operation were compared to aim at clarifying how the difference in operation interface operability will affect the work efficiency in case it is feasible in the future to provide the operator with an operation environment information equal to that available for manned operation (in terms of visual input, sound, vibration, etc.).

Operation interfaces of remote operation were compared with the aim of clarifying how use of the operating lever of the actual machine as the operation interface in current unmanned construction will affect the work efficiency.

\subsubsection{Manned operation}

An operator boarded a hydraulic excavator, used the operating lever of the actual excavator installed in the operation cabin, and conducted ordinary manned operation. (Fig. 2)

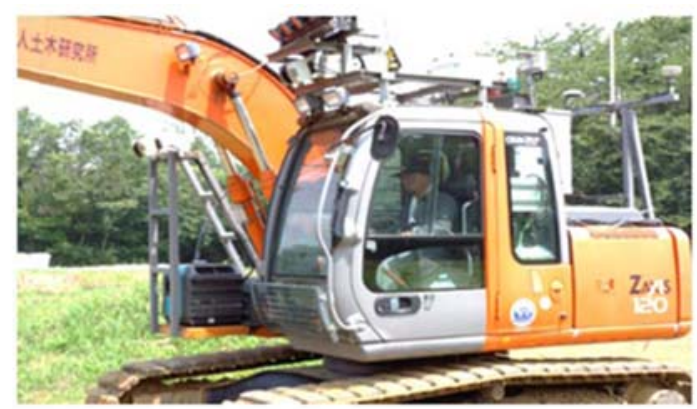

Fig. 2 Boarding operation

\subsubsection{Manned operation with the remote operation device}

An operator boarded a hydraulic excavator and operated the excavator with the remote operation device (to be explained later). (Fig. 3)

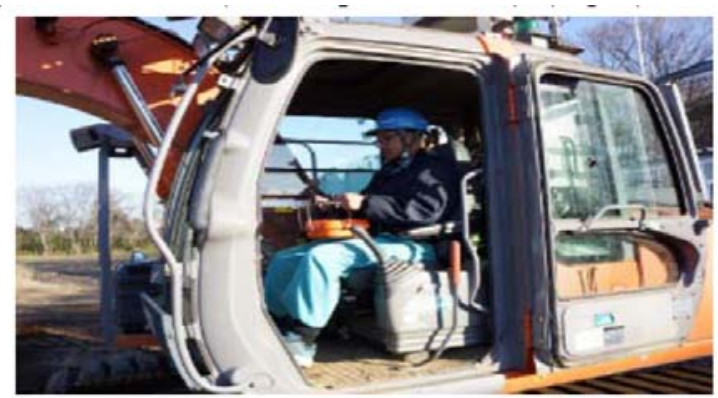

Fig. 3 Boarding operation using the remote control device

\subsubsection{Remote operation using the conventional system}

The conventional system as used here is the typical remote operation method currently used in unmanned construction. The operator conducted remote operation using the remote operation device (to be explained later) while checking the image shown on the video devices as explained in "3.3.2 Video equipment" taken by three cameras in the "operation measurement room" as shown in Fig. 1. (Fig. 4)

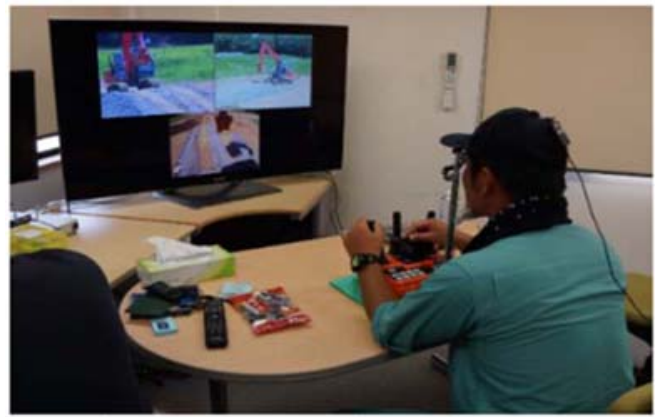

Fig.4 Remote control according to the conventional system

\subsubsection{Operation using the cabin-type remote operation device}

An operator conducted remote operation using the cabin-type remote operation device (to be explained later) while checking the images given by the cameras in the operation measurement room as in Fig. 1. (Fig. 5)

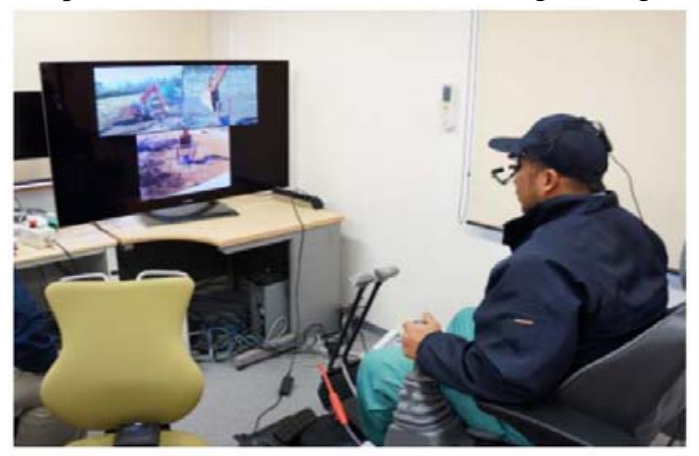

Fig. 5 Cockpit-type remote device

\subsection{Remote operation interface}

In this experiment, two remote operation interfaces, were used in addition to the operating lever and traveling lever of the hydraulic excavator, and their effects on the work efficiency were measured.

\subsubsection{Cabin-type remote operation device}

The operator in the operation cabin, which is equivalent to that of an actual excavator, conducts remote operation using the operating lever and travel lever, the same as those of an actual machine. (Fig. 6) 


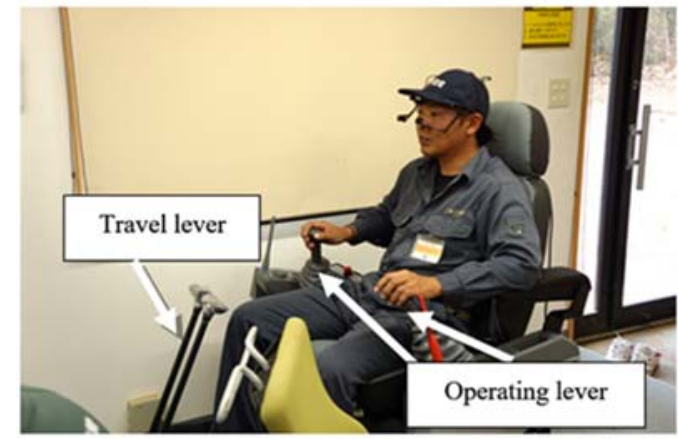

Fig. 6 Cabin-type remote operation device

\subsubsection{Remote operation device}

A typical remote operation device used in conventional remote operation (Fig. 7)

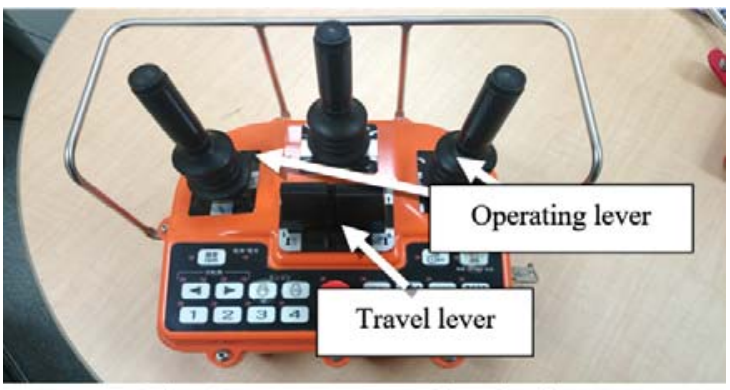

Fig. 7 remote operation device

\subsubsection{Operating angle and neutral range of the lever}

For the cabin-type remote operation device (and the actual lever) and remote operation device, the operating angle and neutral range of the lever were set as shown in Table 1 (default values by the manufacturer).

Table 1 Operating angle of the operating lever Operation lever specifications

\begin{tabular}{|c|c|c|c|}
\hline \multicolumn{2}{|l|}{ Item } & Remote control & $\begin{array}{l}\text { Operating lever and } \\
\text { remote operation cabin }\end{array}$ \\
\hline Operating angle & {$\left[{ }^{\circ}\right]$} & 20.00 & $\begin{array}{r}21.70 \\
\end{array}$ \\
\hline Neutral range & {$[1]$} & 2.50 & 0.81 \\
\hline \multicolumn{4}{|c|}{ Travel lever specifications } \\
\hline \multicolumn{2}{|l|}{ Item } & Remote control & $\begin{array}{l}\text { Operating lever and } \\
\text { remote operation cabin }\end{array}$ \\
\hline Operating angle & [?] & 15.00 & 12.50 \\
\hline Neutral range & ["] & 2.50 & 0.66 \\
\hline
\end{tabular}

\subsection{Operator}

As shown in Table 2, 10 operators with 5 or more years of experience in manned operation of hydraulic excavators participated in the comparison experiment.
Table 2 Age and construction machinery years of experience of operator

\begin{tabular}{|c|c|c|c|c|c|}
\hline Operator & Age & Experience & Operator & Age & Experience \\
\hline No. 1 & 38 years old & 20 years & No. 6 & 30 years old & 15 years \\
\hline No. 2 & 35 years old & 10 years & No. 7 & 32 years old & 10 years \\
\hline No. 3 & 34 years old & 10 years & No. 8 & 31 years old & 15 years \\
\hline No. 4 & 34 years old & 10 years & No. 9 & 39 years old & 15 years \\
\hline No. 5 & 57 years old & 30 years & No. 10 & 46 years old & 20 years \\
\hline
\end{tabular}

\subsection{Measurement and experiment times}

Ten operators repeated the work run set in "3.2 Outline of the model task" ten times for each of the four operation conditions.

The measurement start timing was when the caterpillars of the hydraulic excavator started to rotate as the excavator began to move at the start point in Fig. 1. The end of measurement was when the operator completed the work, returned to the start point, revolved the upper part of the machine, and set the stationary posture.

The cycle time measured in a single operation from the measuring start to end was set as the indicator of work efficiency evaluation. (Work efficiency (\%) = cycle time for manned operation / cycle time of the subject operation condition $\times 100$ )

Another fixed camera was installed separately from the cameras to film videos for remote operation to record the entire view of the work area as a record of the work (Fig. 8).

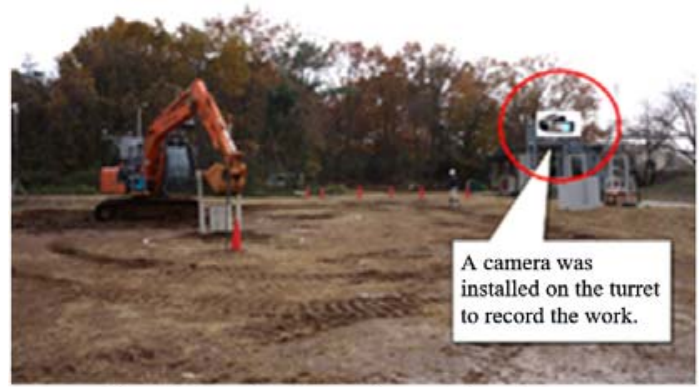

Fig. 8 Installation of work for the camera

\section{Experiment Results}

The experiment results were summarized based on data containing the results of the eight runs, or from the third to the tenth, in which the dispersion of cycle time was sufficiently settled ${ }^{[2]}$. There were 75 sets of measurement data for each of the four operation conditions, and the total number of data sets was 300 (75 $\times 4$ cases). 


\subsection{Comparison of operation interfaces for manned operation}

Based on the obtained results, the two operation methods, or "manned operation" and "remote operation in the machine" were compared.

When comparing the two work methods, one cycle time (measured in seconds) was divided into "work" and "travel," and the "work" was further divided into four elements, or "grabbing (of a solid object)," "lifting and rotating (of the solid object)," "lowering (of the solid object)," and "raising (of the boom and arm)" (see Fig. 9). The thus subdivided cycle time was defined as the "work time" of each division. Cycle time, work time and work efficiency using the manned operation as the benchmark were analyzed as shown in Table 3.

\subsubsection{Comparison results}

When the operation interface was switched from manned operation to the remote operation device, the work efficiency decreased by $30.1 \%$. For "work" and "traveling," the efficiency of the "work" decreased by $36.2 \%$, while that of "traveling” decreased by $25.3 \%$.

Work time greatly differed particularly for some types of jobs, namely "grabbing” and "lowering.”

\subsection{Comparison of operation interfaces for remote operation}

Two operation methods, or "remote operation using the conventional system" and "operation with the cabintype remote operation device" were compared. The subdivided cycle times and the work efficiency with manned operation as the benchmark are analyzed in Table 4 as in the case of " 4.1 Comparison of operation interfaces for manned operation" in comparison of the two work methods.

\subsubsection{Comparison results}

When the remote operation interface was switched from the remote operation device to the cabin-type remote operation device, the work efficiency remained almost the same (up 0.7\%). Work efficiency differences differ between "work" and "traveling." There is a $2.9 \%$ increase in efficiency for "work," while there is a $4.2 \%$ reduction for "traveling."

In terms of cycle time difference, the largest cycle

Table3 Comparison of the interface in the boarding operation

\begin{tabular}{|c|c|c|c|c|c|c|c|c|c|c|c|}
\hline \multirow{3}{*}{ Operation method } & \multirow{3}{*}{$\begin{array}{c}\text { No. of } \\
\text { data } \\
\text { sets }\end{array}$} & \multicolumn{7}{|c|}{ Work time (unit: second) } & \multicolumn{3}{|c|}{ Manned operation } \\
\hline & & \multicolumn{5}{|c|}{ Job } & \multirow{2}{*}{ Travel } & \multirow{2}{*}{ Total } & \multirow{2}{*}{ Total } & \multirow{2}{*}{$\begin{array}{c}\text { Work } \\
\text { efficiency }\end{array}$} & \multirow{2}{*}{ Total } \\
\hline & & Grab & 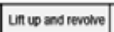 & Lower & Raise & Total & & & & & \\
\hline Manned operation & 75 & 16.8 & 16.7 & 7.9 & 6.6 & 48.1 & 73.5 & 121.6 & $100.0 \%$ & $100.0 \%$ & $100.0 \%$ \\
\hline Maximum & & 33.1 & 22.8 & 35.4 & 11.7 & 82.6 & 102.5 & 180.1 & $100.0 \%$ & $100.0 \%$ & $100.0 \%$ \\
\hline Minimum & & 8.4 & 11.4 & 2.0 & 3.8 & 29.2 & 55.0 & 102.1 & $100.0 \%$ & $100.0 \%$ & $100.0 \%$ \\
\hline Standard deviation & & 5.4 & 2.5 & 4.7 & 1.7 & 11.1 & 10.0 & 15.6 & 0 & 0 & 0 \\
\hline \begin{tabular}{|l|l} 
Operation using remole operaton device on board the machine \\
\end{tabular} & 75 & 26.8 & 22.0 & 16.9 & 9.7 & 75.4 & 98.5 & 173.8 & $63.8 \%$ & $74.7 \%$ & $69.9 \%$ \\
\hline \begin{tabular}{|l|} 
Maximum \\
\end{tabular} & & 65.8 & 35.9 & 49.1 & 21.2 & 131.1 & 134.0 & 245.9 & $130.7 \%$ & $116.3 \%$ & $116.2 \%$ \\
\hline Minimum & & 12.7 & 14.8 & 5.5 & 2.4 & 40.0 & 63.5 & 115.4 & $52.7 \%$ & $36.8 \%$ & $48.5 \%$ \\
\hline \begin{tabular}{|l} 
Standard deviation \\
\end{tabular} & & 9.1 & 4.5 & 8.3 & 3.8 & 18.6 & 19.1 & 33.4 & $14.3 \%$ & $19.6 \%$ & $13.9 \%$ \\
\hline Work time (work efficiency) difference & 75 & 10.0 & 5.4 & 8.9 & 3.0 & 27.3 & 25.0 & 52.3 & $-36.2 \%$ & $-25.3 \%$ & -30.18 \\
\hline Maximum & & -10.9 & -5.4 & -4.5 & -2.8 & -9.1 & -24.1 & -21.9 & $-16.3 \%$ & $-30.7 \%$ & $-16.2 \%$ \\
\hline Minimum & & 42.5 & 17.3 & 34.2 & 15.0 & 68.9 & 61.9 & 121.7 & $63.2 \%$ & $47.3 \%$ & $51.5 \%$ \\
\hline Standard deviation & & 10.0 & 4.5 & 7.7 & 3.5 & 18.9 & 17.5 & 31.6 & $19.6 \%$ & $14.3 \%$ & $13.9 \%$ \\
\hline
\end{tabular}

Table4 Comparison of the interface in the remote operation

\begin{tabular}{|c|c|c|c|c|c|c|c|c|c|c|c|}
\hline \multirow{3}{*}{ Operation method } & \multirow{3}{*}{$\begin{array}{l}\text { No. of } \\
\text { data } \\
\text { sets }\end{array}$} & \multicolumn{7}{|c|}{ Work time (unit: second) } & \multicolumn{3}{|c|}{ Manned operation } \\
\hline & & \multicolumn{5}{|c|}{ Job } & \multirow{2}{*}{ Travel } & \multirow{2}{*}{ Total } & \multirow{2}{*}{ Total } & \multirow{2}{*}{$\begin{array}{c}\text { Work } \\
\text { efficiency }\end{array}$} & \multirow{2}{*}{ Total } \\
\hline & & Grab & un up and revowe & Lower & Raise & Total & & & & & \\
\hline Manned operation & 75 & 50.8 & 35.6 & 31.4 & 20.4 & 138.3 & 124.9 & 263.2 & $37.0 \%$ & $62.0 \%$ & $48.1 \%$ \\
\hline Maximum & & 162.7 & 132.9 & 125.0 & 71.9 & 279.5 & 195.2 & 429.1 & $79.4 \%$ & $101.1 \%$ & $86.6 \%$ \\
\hline Minimum & & 21.3 & 19.9 & 13.6 & 9.2 & 81.9 & 73.8 & 155.7 & $16.1 \%$ & 42.58 & $27.9 \%$ \\
\hline Standard deviation & & 21.8 & 15.7 & 16.6 & 9.0 & 42.9 & 32.7 & 61.8 & $11.6 \%$ & $14.9 \%$ & $10.1 \%$ \\
\hline $\begin{array}{l}\text { Operation using remote operason device on board the } \\
\text { mactine }\end{array}$ & 75 & 50.7 & 33.7 & 22.5 & 19.6 & 126.6 & 132.4 & 258.9 & 39.98 & 57.88 & $48.7 \%$ \\
\hline Maximum & & 108.0 & 61.7 & 59.4 & 46.6 & 212.0 & 206.3 & 399.4 & 77.08 & $91.7 \%$ & $69.5 \%$ \\
\hline Minimum & & 20.8 & 18.9 & 3.1 & 7.2 & 68.1 & 90.9 & 165.8 & $18.0 \%$ & $32.2 \%$ & $26.4 \%$ \\
\hline Standard deviation & & 15.9 & 8.2 & 12.3 & 7.3 & 31.5 & 30.7 & 54.5 & $11.9 \%$ & $11.8 \%$ & $9.9 \%$ \\
\hline Work time (work efficiency) difference & 75 & 0.1 & 1.9 & 8.9 & 0.8 & 11.7 & -7.5 & 4.3 & 2.98 & -4.28 & $0.7 \%$ \\
\hline Maximum & & 113.8 & 95.5 & 107.4 & 46.4 & 157.4 & 68.8 & 134.2 & $27.4 \%$ & $23.9 \%$ & $23.3 \%$ \\
\hline Minimum & & -38.5 & -24.9 & -28.4 & -25.6 & -68.8 & -90.4 & -142.7 & $-31.5 \%$ & -48.68 & $-29.4 \%$ \\
\hline Standard deviation & & 19.7 & 16.2 & 19.8 & 8.7 & 38.3 & 36.4 & 54.0 & $10.0 \%$ & $15.8 \%$ & $9.5 \%$ \\
\hline
\end{tabular}


time difference occurred in the "lowering" job of the "work," while no major difference occurred for other jobs.

\section{Discussion and Summary}

\subsection{Comparison of operation interfaces for manned operation}

\subsubsection{Relationship with operator skills}

The swiftness of manned operation cycle time is defined as the skill of the operator. In order to clarify whether there is any correlation between the operator's skill and the work efficiency differences that occurred as a result of comparison, verification needs to be conducted.

To be specific, the cycle time of manned operation (operator's skill) and the work efficiency differences were subjected to regression analysis based on the scatter diagram prepared as in Fig. 9. The result of analysis gives a correlation factor of 0.23 . Since this is low enough, it is judged there is no correlation.

\subsubsection{Causes of work efficiency differences}

Of 75 sets of data, three of those with the work efficiency differences closer to the median were picked up at random.

For "grabbing," "lowering," and "traveling," for which cycle time differences frequently occur among the three sets of data, the difference in behavior of the hydraulic excavator between "manned operation" with the actual lever and "remote operation by the operator on board the machine" using a remote operation device was checked based on the recorded video to examine what causes work efficiency differences.

It was revealed that manned operation with a remote operation device was a complex motion (that is, two or more motions, such as opening of the bucket and raising of the boom, simultaneously conducted) like the operation using the actual lever. It is presumed that differences in individual operators' adaptability to the difference in the layout or sensitivity of the lever affect the work efficiency differences.

For "traveling," the excavator followed almost the same track despite some lateral deviation regardless of the difference in operation, or manned operation with the actual lever and manned operation with a remote operation device. However, the time gap in "traveling" was attributable to the differences in time taken to adjust the traveling direction and in the traveling speed.
What causes this difference is considered to be the adaptability of individual operators to the interfaces as in the case of "grabbing” and "lowering."

\subsubsection{Summary}

Information from the environment necessary for executing the model task shares the same conditions for any cases of manned operation. The difference in the operation interfaces, however, caused differences in cycle time.

According to the scatter diagram of Fig. 9, no correlation was found for the work efficiency differences between the differences in the operator's skill and the operation interfaces. At least according to what the dispersion of work efficiency differences indicates, there is a small difference in the skill about operation of the lever in manned operation. When the remote operation device is used, however, differences in work efficiency occurred. This is presumably because the operators failed to adapt to the operation interface depending on the difference in the layout of the lever or the motion reaction speed.

Therefore, experienced operators who were familiar with manned operation, the subject of the study, were affected in terms of work efficiency by changes in the operation interfaces even though they do the same work. The degree of such effect is assumed to vary depending on how each operator can adapt to the difference in operation interfaces.

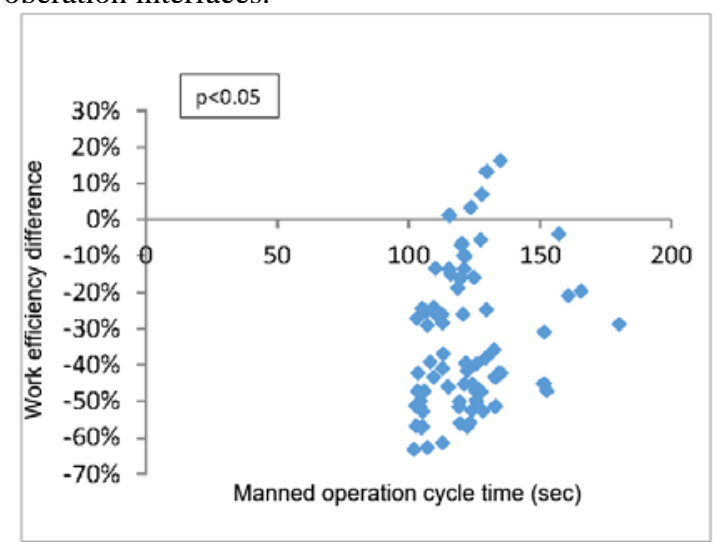

Fig. 9 Boarding operation time and work efficiency difference due to the difference in the operation interface

\subsection{Comparison of operation interfaces for remote operation}

\subsubsection{Relationship with operator skill}

The swiftness of remote operation cycle time is 
defined as the skill of the operator. A scatter diagram was prepared as in Fig. 10 to conduct regression analysis in order to clarify whether or not there is any correlation between the operators' skill and the work efficiency differences determined by comparison. As the regression analysis gives 0.50 for the correlation factor, it is judged that there is a positive correlation of medium strength.

Since a decision function (R2) is low, at 0.24 , the regression equation is not high enough in precision but is understood to be able to show the overall trend. Work efficiency differences caused by the difference in the operation interfaces for manned operation are presumed to be affected by the skill of the operator.

In order to clarify which job of the model task makes the operator's skill affect the work efficiency difference, 75 sets of cycle time data about "remote operation using the conventional system" were ranked based on the criterion that those with shorter cycle time are higher in rank. The 75 sets of data were categorized into three - higher, middle, and lower — with each having 25 sets, and the comparison results were rearranged as in Table 5 .

For the "work" category, the longer the cycle time of "remote operation using the conventional system," a greater improvement is seen in work efficiency when the operation interface is switched to the cabin-type remote operation device. On the other hand, the shorter the cycle time of "remote operation using the conventional system," the less effective it is.

For "traveling," the work efficiency of the higher ranking data shows an $11.7 \%$ reduction, while the efficiency is almost the same for middle and lower ranking data.

\subsubsection{Causes of work efficiency differences}

To understand what caused the work efficiency differences as in Table 5, three sets of data whose "work" and "traveling" data were close to the median were picked up each from the higher ranking, middle ranking and lower ranking groups. A total of six sets of data were thus selected. The behavior of the hydraulic excavator in those six sets of data was checked from the video records about "remote operation using the conventional system" and "operation with the cabintype remote operation device," which are subject to comparison in our study, in order to look for what caused the work efficiency differences.

The result revealed that "shut-down time during oneto two-second-long work suspension time" and "sudden start and stop" are what caused the cycle time differences in the lower ranking group. Not many delay cases by these causes are seen in the middle ranking group. Almost no such cases are seen in the higher ranking group. No operation by complex motion is almost seen in any group.

For "traveling," over 10\% differences occurred only in the upper ranking group. There is, however, no major difference in operational behavior between operation with the cabin-type remote operation device and operation with the remote operation device in either the higher, middle or lower ranking group.

For the higher ranking group, the excavator moves slower when operated with the cabin-type remote operation device. The operator uses the actual traveling lever when operating the machine with the cabin-type remote operation device. In this case, the operators need to operate the lever located at their foot with a headforward posture. As the work monitor is located at the front, the operators need to watch this front monitor. This means the operators have to operate without checking how they are holding the lever. This makes them feel careful about driving the machine, which presumably causes slower traveling of the machine.

It is estimated that no major influence occurred to the middle and lower ranking groups because the speed is lower in the first place for those groups.

\subsubsection{Summary}

According to the scatter diagram in Fig. 10, there is a tendency for a positive correlation in the difference in cycle time between operation with the remote operation device conventionally used in unmanned construction and that with the cabin-type remote operation device although the corroborating data are small in number.

It is found that operators who show a longer cycle time in operation with the remote operation device typically used in unmanned construction and find it difficult to adapt to remote operation shortened the cycle time and improved work efficiency when they switched to operation with the cabin-type remote

Table5 Comparison of the interface in the remote operation (divided by skill)

\begin{tabular}{|c|c|c|c|c|c|c|c|c|c|}
\hline \multirow{2}{*}{$\begin{array}{c}\text { Remote } \\
\text { operation cycle } \\
\text { time }\end{array}$} & \multirow{2}{*}{$\begin{array}{c}\text { No. of } \\
\text { data sets }\end{array}$} & \multicolumn{5}{|c|}{ Cycle time } & \multicolumn{3}{|c|}{ Work efficiency difference } \\
\hline & & Grab & Lift and revolve & Lower & Raise & Grab & Work & Travel & Grab \\
\hline Higher ranking & 25 & -5.8 & -1.5 & 2.9 & -0.5 & -22.8 & $-1.4 \%$ & $-11.7 \%$ & $-5.2 \%$ \\
\hline Middle ranking & 25 & -0.9 & -3.1 & 9.1 & -2.2 & 1.6 & $3.1 \%$ & $1.3 \%$ & $2.6 \%$ \\
\hline Lower ranking & 25 & 7.1 & 10.2 & 14.8 & 5.0 & 33.9 & $7.0 \%$ & $-2.2 \%$ & $4.6 \%$ \\
\hline Grand total & & 0.1 & 1.9 & 8.9 & 0.8 & 4.3 & $2.9 \%$ & $-4.2 \%$ & $0.7 \%$ \\
\hline
\end{tabular}




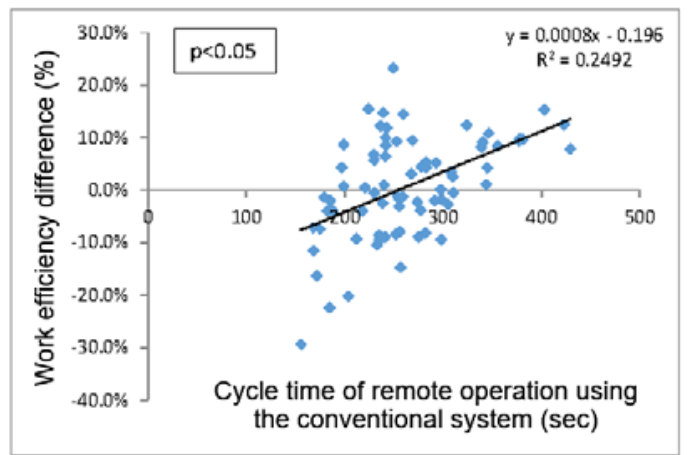

Fig. 10 Remote operation time and work efficiency difference due to the difference in the operation interface

operation device.

On the other hand, operators who show a shorter cycle time with operation with the remote operation device used in unmanned construction and can sufficiently adapt to remote operation turned out to show no reduction in cycle time when switched to operation with the cabin-type remote operation device.

The experiment results suggest that there are operators who do not depend on operation interfaces and others who depend on the operation interface similar to that of manned operation.

In conclusion, a certain work efficiency improvement or stability improvement may result from applying the shape or layout of the operating lever of an actual machine to the operation interface of remote operation.

It is also suggested that there are operators who have a significant capability to adapt to remote operation.

\section{Conclusion}

Switching the operation interface of current unmanned construction to the actual operating lever is effective for improving work efficiency only in a limited manner, but is considered to be effective as a remediation for operators slower in remote operation. There is still room for review about the layout of the traveling lever.

According to the results of our research that focused on the effect of operation interface operability for manned operation on work efficiency (a work efficiency reduction of $30 \%$ on average for the entire operation), improvement of the operation interface is considered to be an essential task to tackle in the future for unmanned construction that is predicted to become closer to manned construction in the years to come.

\section{References}

[1] Masaharu Moteki, Shinichi Yuta, Kenichi Fujino: The Proposal of the Model Task for Efficiency Evaluation of the Construction Work by Remote Control of a Hydraulic Excavator, paper in the Journal of JCMA, Vol. 66, No. 8, pp.71 - 79, 2014 Akihiko Nishiyama, Masaharu Moteki, and Kenichi Fujino: Research on the Comparison of Operator Viewpoints between Remote Control and Manned Operation in Unmanned Construction with Hydraulic Excavator, the 12th Symposium on Construction Robotics in Japan

[2] Masaharu Moteki, Kenichi Fujino, and Akihiko Nishiyama: Research on Proficiency of remote operation of Construction Machinery - Discussion on Work Efficiency and Accuracy for Manned Operation and remote operation of Construction Machinery, Proceedings and Summaries of the 2012 Construction Execution and Construction Machinery Symposium, pp. 19-24, 2012

[3] Akihiko Nishiyama, Masaharu Moteki, Kenichi Fujino, and Takeshi Hashimoto: Research On The Comparison Of Operator Viewpoints Between Manned And Remote Control Operation In Unmanned Construction Systems, the 30th International Symposium on Automation and Robotics in Construction, 2013

[4] Masaharu Moteki, Kenichi Fujino, and Takashi Otsuki: Diffusion of Unmanned Construction Technology to Construction Sites and Future Technical Needs - Validation Experiment Report for remote operation System, Proceedings of the 12th Symposium on Construction Robotics in Japan, pp. 89-96, 2010 